\title{
Persepsi Masyarakat Berbasis Neurosains di Desa Wisata Rawabogo
}

\section{Muhamad Ramdani Pamungkas", Imam Indratno}

Prodi Perencanaan Wilayah dan Kota, Fakultas Teknik, Universitas Islam Bandung, Indonesia.

*mrampads@gmail.com, akudandiriku1@gmail.com

\begin{abstract}
Rawabogo Village is one of the tourist villages in Bandung Regency which was determined based on the decision of the Bandung Regency regent in 2011. Tourism conditions in Rawabogo Tourism Village such as amenities and accessibility, as well as complementary tourism facilities are not adequate. In addition, the communication problem from each key actor causes different perceptions of tourism development in Rawabogo Village. These conditions can affect perceptions, emotions, motivations, expectations, as well as services and products offered by destinations from tourists or the public. One way to verify responses and perceptions can be done using neuroscience methods by measuring electroencephalography (EEG) waves. This study uses gamma waves to measure response, because these waves are closely related to high-level brain activation. The results obtained, village government respondents tend to get tourism development benchmarking, village communities from the results of canals AF7 and AF8 only focus on cultural development, custom peoples are the only group that has high spatial experience of the Nagara Padang site based on TP9 and TP10 channels, and for public resident tend not to form a memory of the space based the stimulus. Based on the perception responses obtained.
\end{abstract}

Keywords: Neuroscience, Perception, Tourism Village.

Abstrak. Desa Rawabogo merupakan salah satu desa wisata di Kabupaten Bandung yang ditetapkan berdasarkan keputusan bupati Kabupaten Bandung pada tahun 2011. Kondisi pariwisata di Desa Wisata Rawabogo seperti amenitas dan aksesibilitas, serta fasilitas pelengkap pariwisata belum memadai. Selain itu adanya jarak komunikasi dari setiap aktor kunci menyebabkan adanya perbedaan persepsi terhadap pengembangan wisata di Desa Rawabogo. Kondisi tersebut bisa mempengaruhi persepsi, emosi, motivasi, ekspektasi, serta jasa dan produk ditawarkan destinasi dari wisatawan atau masyarakat. Salah satu cara verifikasi respons dan persepsi bisa dilakukan menggunakan metode neurosains dengan pengukuran gelombang elektroensefalografi (EEG). Penelitian ini menggunakan gelombang gamma untuk mengukur respons, dikarenakan gelombang tersebut erat kaitannya terhadap aktivasi otak tingkat tinggi. Hasil yang didapatkan, responden pemerintah desa cenderung mendapatkan benchmarking pengembangan wisata, masyarakat desa dari hasil kanal AF7 dan AF8 hanya fokus terhadap pengembangan budaya, masyarakat adat satu-satunya kelompok yang memliki pengalaman ruang tinggi terhadap situs Nagara Padang berdasarkan kanal TP9 dan TP10, dan pada kelompok masyarakat umum cenderung tidak terbentuk memori terhadap ruang dari stimulus.

Kata Kunci: Neurosains, Persepsi, Desa Wisata. 


\section{A. Pendahuluan}

Desa wisata merupakan bagian dari kawasan perdesaan yang memiliki potensi secara tradisi dan kebudayaan atau melalui kondisi alam dan lingkungan yang mendukung sebagai daerah tujuan wisata. Desa Rawabogo merupakan salah satu desa wisata di Kecamatan Ciwidey, Kabupaten Bandung. Pada tahun 2011, Desa Rawabogo menjadi salah satu dari sepuluh desa wisata di Kabupaten Bandung yang ditetapkan berdasarkan Keputusan Bupati Kabupaten Bandung. Desa Wisata Rawabogo dikenal akan kebudayaannya, serta adanya situs Gunung Nagara Padang yang menjadi daya tarik bagi wisatawan melalui proses upacara peziarahan. Selain Situs Gunung Nagara Padang terdapat potensi wisata lainnya seperti di bidang peternakan kelinci, pertanian, perikanan, dan kerajinan tangan. Dibalik potensi wisatanya dan ditetapkannya menjadi desa wisata, terdapat beberapa permasalahan khususnya dalam amenitas dan aksesibilitas yaitu kondisi jalan rusak berlubang, akses transportasi umum menuju desa tidak ada, penginapan dan toilet umum belum memadai, serta tidak adanya bangunan umum tempat kegiatan berwisata. Selain itu adanya gap komunikasi dari aktor pengembang pariwisata menyebabkan adanya perbedaan persepsi terhadap pengembangan wisata di Desa Rawabogo. Hal ini tentunya akan mempengaruhi persepsi serta emosi, motivasi, ekspektasi, serta jasa dan produk ditawarkan destinasi dari wisatawan atau masyarakat.

Pemahaman terhadap persepsi berguna untuk memahami dan mencari tahu apa yang masyarakat pikirkan dan rasakan serta mengurangi kesalahpahaman dalam penafsiran. Beberapa penelitian dalam mengukur persepsi masyarakat masih menggunakan pengukuran klasik. Pengukuran klasik, seperti kuesioner, memiliki risiko memanipulasi jawaban mereka secara sadar dikarenakan seseorang bisa dengan bebas mengekspresikan persepsinya terhadap suatu obyek. Padahal respons seperti emosi, pengambilan keputusan, persepsi, memori merupakan pikiran bawah sadar. Salah satu cara mengukurnya yaitu melalui penerapan neurosains. Neurosains merupakan ilmu yang mampu menjelaskan bagaimana fungsi otak dan perubahannya, serta mampu mengetahui bagaimana kinerja pikiran bawah sadar. Salah satu cara mengukurnya yaitu melalui penerapan neurosains. Mengetahui respons preferensi melalui sistem sadar otak dapat membantu manajerial dan perencanaan pariwisata dalam merencanakan dan mengambil keputusan, memberikan pengalaman pariwisata dan meningkatkan kinerja pariwisata, terlebih penggunaan neurosains belum digunakan dalam pengembangan Desa Wisata.

Hasil dari pengukuran persepsi tersebut bisa menjadi salah satu rujukan dalam mengetahui kondisi dan apa yang bisa dikembangkan dari desa wisata tersebut. Salah satu alat pengukuran pada neurosains yaitu elektroensefalograf (EEG). EEG merupakan alat pemindaian otak yang menggunakan sensor untuk menangkap sinyal yang dihasilkan dari aktivitas otak. Sehingga dalam penelitian ini penggunaan neurosains digunakan untuk mengukur respons persepsi masyarakat terhadap kondisi Desa Wisata Rawabogo, dan diharapkan pengelola pariwisata mampu memenuhi kebutuhan berwisata wisatawan, maupun bagi masyarakat dan pengelola desa wisata dalam arah pengembangannya.

Berdasarkan latar belakang yang telah diuraikan, maka perumusan masalah dalam penelitian ini sebagai berikut: "bagaimana persepsi kondisi pariwisata di Desa Rawabogo berdasarkan pengukuran elektroensefalografi?”. Selanjutnya, tujuan dalam penelitian ini yaitu: "untuk mengidentifikasi persepsi kondisi pariwisata di Desa Wisata Rawabogo sebagai pemenuhan kebutuhan pariwisata berdasarkan pengukuran elektroensefalografi." 


\section{B. Metodologi Penelitian}

Neurosains adalah ilmu multidisiplin yang memiliki metodologi dinamis dengan menganalisis sistem saraf mengenai dasar-dasar kesadaran, persepsi, memori, dan pembelajaran. Salah satu bidang yang berkembang dari neurosains yaitu di bidang pariwisata (neurotourism). Neurotourism muncul dikarenakan adanya potensi kegiatan pariwisata yang multidisiplin dan beriringan dengan manajemen, ekonomi, pemasaran, psikologi, sosiologi dan estetika, mengeksplorasi mekanisme otak dan saraf didasari untuk mempelajari perilaku wisatawan. Adopsi neurosains dalam neurotourism pun relevan digunakan untuk mengetahui persepsi wisatawan dalam pengambilan keputusan berdasarkan emosi mereka. Alat yang bisa digunakan dalam pengukuran neurosains yaitu electroencephalography (EEG). EEG yaitu alat pemindaian otak yang menggunakan sensor untuk menangkap sinyal yang dihasilkan dari aktivitas otak. EEG diukur di bagian kulit kepala dan menangkap medan listrik yang dihasilkan otak besar. EEG mampu menangkap lima jenis frekuensi yaitu Delta $(4 \mathrm{~Hz})$, Theta $(4-8 \mathrm{~Hz})$, Alpha $(8-13 \mathrm{~Hz})$, Beta $(13-30 \mathrm{~Hz})$, dan Gamma (diatas $30 \mathrm{~Hz})$. Penelitian ini berfokus terhadap kondisi pariwisata di Desa Wisata. Bastiyani \& Safitri, (2013) mengindikasikan empat komponen utama yang perlu dikembangkan, yaitu atraksi berupa atraksi yang bersifat alami, produk fisik dan perilaku masyarakat, akomodasi seperti tempat tinggal sementara dan pemenuhan kebutuhan pelayanan lainnya, aksesibilitas atau fasilitas transportasi yang layak, dan unsur pelayanan lainnya seperti unsur institusional dan masyarakat, fasilitas pelayanan seperti informasi pariwisata, jaringan komunikasi, air bersih, dan-lain-lain.

Penelitian ini menggunakan perangkat Muse 2, yang digunakan sebagai bandana atau headset elektroda di kulit kepala sampai belakang telinga. Perangkat ini mampu merekam EEG yang disalurkan ke dalam lima kanal dengan elektroda di saluran F3, F4, T7, T8, dan PZ. Perangkat ini mampu merekam aktivitas otak di bagian depan (frontal cortex) dan di bagian samping (temporal cortex). Metode pengumpulan data dilakukan dengan melibatkan responden dari berbagai stakeholder di Desa Wisata Rawabogo, responden yang terlibat terdapat pada Tabel 1.

Tabel 1. Target Responden dan Informasi

\begin{tabular}{|c|c|}
\hline Target Responden & Target Informasi didapatkan \\
\hline Pemerintah Desa & \multirow{4}{*}{$\begin{array}{ll}\text { - } & \text { Kondisi Desa dan Kondisi } \\
& \text { Pariwisata Desa Rawabogo } \\
\text { - } & \text { Pengambilan data gelombang EEG } \\
\text { - } & \text { Penilaian kondisi pariwisata }\end{array}$} \\
\hline Kelompok Sadar Wisata & \\
\hline Kelompok Masyarakat Adat & \\
\hline Masyarakat Desa Rawabogo & \\
\hline $\begin{array}{l}\text { Responden tidak mengetahui tentang } \\
\text { Desa Rawabogo }\end{array}$ & $\begin{array}{ll}\text { - } & \text { Pengambilan data gelombang EEG } \\
\text { - } & \text { Verifikasi data EEG }\end{array}$ \\
\hline
\end{tabular}

Sumber: Data Penelitian yang Sudah Diolah. 2021

Dalam pengumpulan data, responden akan diberikan stimulus berupa video kondisi desa dan pariwisata di Desa Rawabogo selain itu terdapat visual berupa kondisi pariwisata di Desa Nglanggeran, Yogyakarta. Desa Nglanggeran dipilih dikarenakan memiliki karakteristik pariwisata dan geografis yang mirip dengan Desa Rawabogo, dan visual wisata suku Maori di Selandia Baru, visual ini untuk menunjukkan bagaimana kegiatan adat dapat ditransformasi ke dalam bentuk kegiatan wisata. Alur stimulus video terdapat pada Tabel 2. 
Tabel 2. Alur Skenario Pengambilan Data pada Stimulus Video

\begin{tabular}{|c|c|}
\hline Detik & Keterangan \\
\hline 0-10 & Blackscreen \\
\hline 11-75 & Kondisi Pariwisata Desa Rawabogo \\
\hline $\mathbf{7 6 - 1 3 1}$ & Kondisi Pariwisata Desa Nglanggeran \\
\hline 132-150 & Blackscreen \\
\hline $151-153$ & Komparasi Kondisi Pariwisata \\
\hline $\mathbf{1 5 3 - 1 6 9}$ & Blackscreen \\
\hline $\mathbf{1 7 0 - 1 7 5}$ & Selesai \\
\hline
\end{tabular}

Sumber: Data Penelitian yang Sudah Diolah. 2021

Di akhir pengambilan data EEG dilakukan wawancara mengenai stimulus video yang ditampilkan serta mengenai rencana pengembangan wisata di Desa Rawabogo sebagai bentuk verifikasi. Pengolahan data dilakukan menggunakan Matlab, program ekstensi tambahan Matlab yaitu EEGLAB, serta Microsoft Excel. Proses pengolahan utama dari data digunakan melalui EEGLAB. Setelah dilakukan analisis data EEG penulis melakukan analisis deskriptif kualitatif. Metode deskriptif kualitatif merupakan suatu metode yang digunakan untuk meneliti suatu objek, kondisi, sistem pemikiran fenomena. Tujuan dari penelitian deskriptif agar penulis lebih bisa mendeskripskan, menggambarkan, fakta secara akurat, faktual dan sistematis mengenai sifat-sifat serta hubungan antarfenomena yang diselidiki.

\section{Hasil dan Pembahasan}

Persepsi lahir dari adanya atensi, memori serta kognisi dari setiap manusia yang terhubung satu sama lain. Jenis gelombang yang digunakan hanya gelombang Gamma, Beta dan Alpha, dan Theta namun gelombang yang lebih diperhatikan yaitu gelombang gamma. Steven Warner menyebutkan jika gelombang gamma muncul ketika adanya proses persepsi penuh terhadap suatu objek, serta muncul ketika terjadinya proses pengolahan informasi, selain itu banyak terlibat dalam proses memori. Warner pun berpendapat gelombang gamma menunjukkan adanya peningkatan atensi dan daya pikir. Menurut Warner gelombang gamma yang dapat ditemukan di setiap bagian otak yaitu antara $36-45 \mathrm{~Hz}$, sehingga penelitian ini hanya melihat gelombang sampai rentang $45 \mathrm{~Hz}$.

\section{Hasil Pengukuran Gelombang}

Hasil pengolahan data menunjukkan setiap responden memiliki persepsi, berdasarkan kognisi, memori serta atensi yang berbeda terhadap ruang yang menjadi stimulus. Hasil dari gelombang setiap responden terdapat pada Gambar 1. 


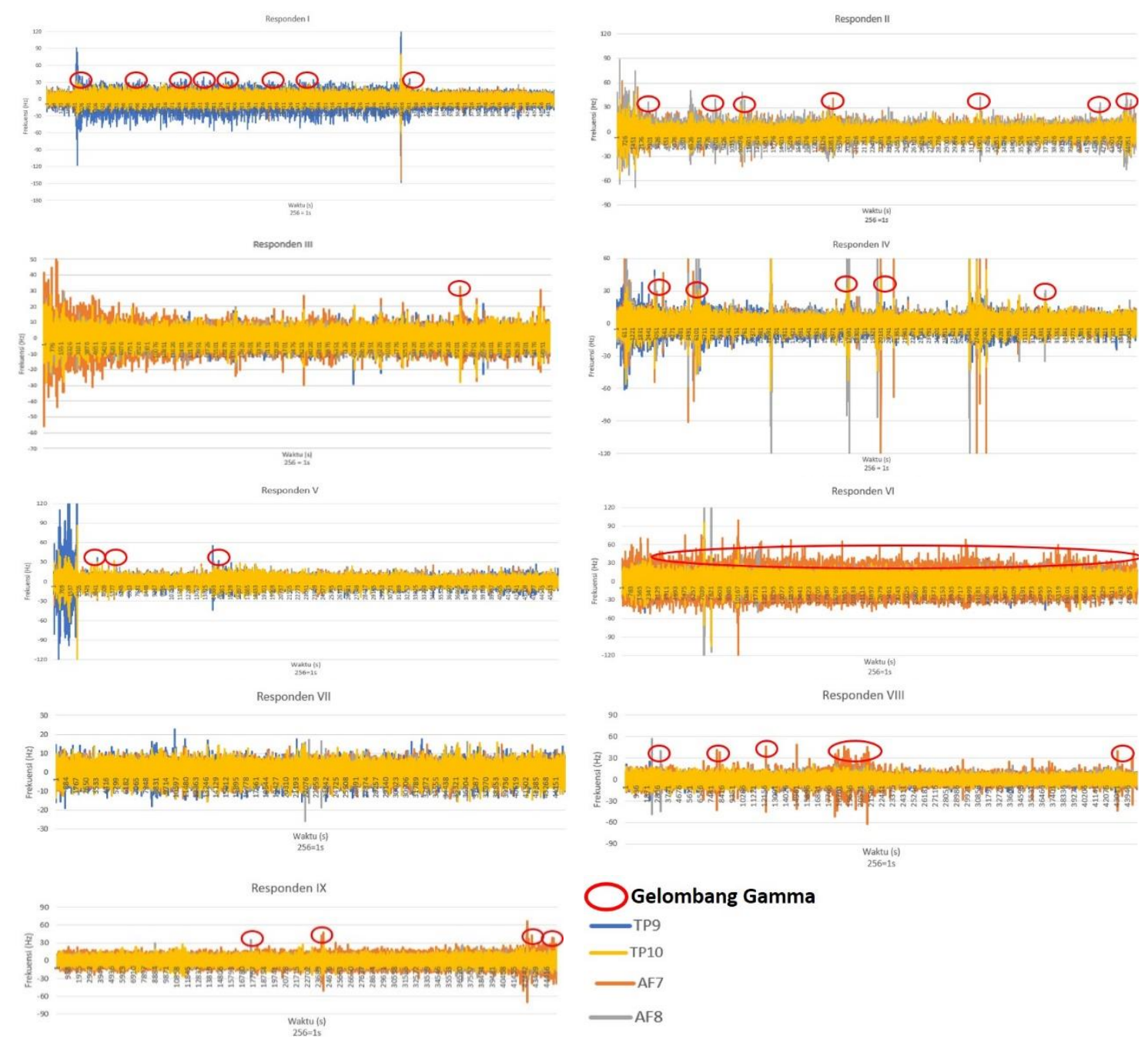

Gambar 1. Hasil Pengukuran EEG

Stimulus visualisasi video dapat memodulasi aktivitas neuron di area temporal dan frontal menjadi lebih aktif, yang disebabkan karena adanya efek transien stimulus visualisasi video pada jalur sensori sebagai adaptasi alami terhadap kondisi yang diamati, terlihat dari adanya perbedaan terhadap gelombang [21]. Pada kanal AF7 dan AF8 atau pada bagian frontal cortex identik sebagai pusat berpikir, atensi, imajinasi sampai motivasi. Sedangkan pada kanal TP9 dan TP10 atau pada bagian temporal cortex erat kaitannya pada fungsi pendengaran, proses dari memori jangka panjang, memori visual atau Warner menyebutnya sebagai persepsi visual dari objek. Jika dikaitkan dengan gelombang gamma sebagai gelombang yang dinilai maka adanya keselarasan dengan bagian frontal cortex yang aktif dikarenakan gelombang gamma dikaitkan terhadap kegiatan-kegiatan ketika konsentrasi dan atensi yang tinggi dan pada temporal gelombang gamma aktif ketika adanya proses memori.

\section{Perbandingan Respons Responden}

Perbandingan responds dari setiap responden dilakukan untuk melihat lebih jauh keefektifan dari stimulus yang telah disusun, dan bagaimana respons dari bagian otak terhadap stimulus tersebut, terlebih untuk mengetahui bagaimana persepsi mereka terhadap ruang yang ditampilkan dari stimulus, karena ruang memberikan makna tertentu, sehingga makna ruang menjadi bagian integral dalam suatu proses perencanaan 
penulis membedakan hasil pengolahan data pada setiap responden [22].

\section{Responden Pemerintah Desa}

Penulis memetakan responden pemerintah desa yaitu responden yang berasal dari perangkat desa (Responden I) serta berasal dari Pokdarwis (Responden II). Hasil respons EEG dari kedua responden hampir memiliki kesamaan, pada kanal AF7 dan AF8 ditemukan adanya gelombang gamma yang dihasilkan pada detik ke-11 yaitu saat visual awal Desa Rawabogo, namun pada responden II terlihat adanya atensi pada potensi kopi di Desa Rawabogo, kesenian di Desa Nglanggeran, dan pada visual komparasi amenitas. Pada kanal TP9 dan TP10 keduanya memilki fokus yang berbeda, pada responden I terdapat gelombang gamma pada kesenian di Desa Nglanggeran, sedangkan pada responden II terjadi saat visual panorama alam dari Nagara Padang. Sejatinya bagian otak saling terkait satu sama lain, keterkaitan antara setiap kanal dan adanya perbedaan hasil yang terjadi memberikan pandangan jika adanya memori, atensi serta kognisi yang berbeda dari responden sehingga terciptanya persepsi yang berbeda pula. Bentuk respons yang dihasilkan bisa diasumsikan adanya penggambaran tak sadar dan bentuk perwujudan ruang dalam kecenderungan untuk mengembangkan wisata dari potensi yang ada di Desa Rawabogo, dan proses benchmarking dalam pengembangan wisata di Desa Wisata Rawabogo dari visual di Desa Nglanggeran dan Suku Maori.

\section{Responden Masyarakat Adat}

Berdasarkan hasil EEG responden masyarakat adat (Responden IV-VI) di Desa Rawabogo, terdapat perbedaan terhadap responden non masyarakat adat. Pada kanal TP9 dan TP10, setiap responden masyarakat adat terdapat gelombang gamma yang dihasilkan pada visual yang berlokasi di Nagara Padang, khususnya saat visual upacara adat atau ziarah, hal tersebut tidak ditemukan pada responden lain di luar masyarakat adat, memori atau bentuk respons yang diterima oleh masyarakat adat terhadap situs Nagara Padang cenderung aktif saat visual tersebut dilihat. Hal tersebut bisa terkait dari adanya bentuk pengalaman ruang yang tinggi dari masyarakat adat. Sedangkan pada kanal AF7 dan AF8 setiap responden memiliki bentuk atensi yang berbeda. Seperti pada responden IV munculnya EEG pada kesenian musik di Desa Nglanggeran merupakan bentuk perhatian khusus dikarenakan responden IV merupakan seorang pemusik di Desa Rawabogo. Sedangkan adanya bentuk gelombang yang tinggi dari responden VI bisa dikarenakan adanya bentuk ketertarikan sejak dimulainya stimulus atau ada noise dari kondisi internal atau eksternal responden yang ikut terekam. Adanya gambaran dari respons masyarakat adat diasumsikan jika intensionalitas dan pengalaman ruang masyarakat adat terhadap Nagara Padang merupakan ciri jika Nagara Padang mempunyai value tersendiri bagi kelompok masyarakat adat.

\section{Responden Masyarakat Desa}

Hasil EEG dari responden III atau sebagai responden masyarakat rawabogo memberikan nilai TP9 dan TP10 tanpa adanya gelombang gamma yang dihasilkan, ini bisa berarti pula tidak adanya rekognisi memori terhadap visual yang ditampilkan. Sedangkan pada kanal AF7 dan AF8 hanya tertarik pada satu waktu yaitu pada visual kesenian di Suku Maori. Fenomena tersebut diasosiakan jika pengembangan potensi budaya atau heritage (warisan budaya) yang bisa menjadi potensi berharga untuk dikembangkan di Desa Wisata Rawabogo, dikarenakan Heritage adalah sesuatu yang diturunkan dari generasi ke generasi dan ini menjadi identitas suatu masyarakat dan negara [23], keatifan lokal yang berupa tradisi primordial Indonesia memberikan nilai dan pandangan yang menyatu dengan alam semesta [24], sehingga bentuk pengembangan budaya memang menjadi nilai tersendiri bagi Desa Wisata Rawabogo, dan Desa Rawabogo bisa menjadi 
Desa Wisata dikarenakan adanya warisan budaya tersebut.

\section{Responden Masyarakat Umum}

Responden masyarakat umum yaitu responden VII, VIII, IX memiliki hasil EEG yang hampir serupa pada kanal AF7 dan AF8. Setiap responden memiliki tingkat dan jumlah atensi yang berbeda pada setiap visual, namun pada responden VIII dan IX memiliki kesamaan yaitu pada visual kopi di Rawabogo dan pada visual perbandingan kesenian di tiga lokasi, serta wisata alam di Desa Nglanggeran. Sedangkan pada responden VII tidak terbentuknya gelombang gamma bisa diakibatkan adanya faktor internal dari kondisi responden sehingga tidak mendapatkan fokus atau memang tidak tertarik dengan stimulus visual yang diberikan. Sedangkan pada hasil rekaman gelombang otak dari responden masyarakat umum pada kanal TP9 dan TP10 tidak terjadi gelombang dengan frekuensi yang mencapai frekuensi gamma $(>30 \mathrm{~Hz})$, dikarenakan bisa jadi belum adanya rekognisi memori yang pernah diterima atau belum terciptanya pengalaman ruang pada suatu tempat yang menyerupai atau memang belum mengenal setiap lokasi yang ada di setiap stimulus. Tidak munculnya gelombang yang dihasilkan menunjukkan belum dikenalnya Desa Rawabogo sebagai pilihan destinasi wisata bagi kelompok responden masyarakat umum. Sehingga pihak pengelola memerlukan marketing dan branding terhadap Desa Wisata Rawabogo agar bisa lebih dikenal masyarakat secara luas.

\section{Kesimpulan}

Berdasarkan penelitian yang telah dilakukan terdapat beberapa kesimpulan. Secara garis besar persepsi dihasilkan berdasarkan memori, atensi, serta kognisi yang dibentuk dari adanya hasil kerja stimulan fungsi otak yang bekerja secara paralel dalam memberikan interpretasi dari objek yang dilihat yang dipengaruhi oleh kondisi lingkungan, kondisi internal responden serta akurasi stimulus yang digunakan. Respons dari kelompok pemerintah desa cenderung lebih bisa mendapatkan atensi terhadap kondisi potensi yang dapat dikembangkan seperti pada potensi agrowisata (kopi), alam, sampai budaya yang ada, serta terhadap visual yang dihasilkan di Desa Nglanggeran dan Suku Maori. Bentuk persepsi berdasarkan atensi dan memori yang dihasilkan bisa menjadi benchmarking terhadap pengembangan wisata di Desa Rawabogo. Respons masyarat Desa Rawabogo menghasilkan gelombang gamma pada kanal AF7 dan AF8 pada penampilan budaya di Suku Maori saja sedangkan tidak menghasilkan gelombang gamma pada kanal TP9 dan TP10, fenomena tersebut diasosiakan jika pengembangan potensi budaya merupakan hal yang paling untuk dikembangkan di Desa Wisata Rawabogo. Selanjutnya, respons kelompok masyarakat adat merupakan satu-satunya kelompok responden yang menghasilkan gelombang gamma pada visual di Situs Nagara Padang pada kanal TP9 dan TP10, hal ini disebabkan adanya memori dan pengalaman ruang yang tinggi dari masyarakat adat terhadap Situs Nagara Padang. Terakhir, respons kelompok masyarakat umum tidak memiliki gelombang gamma yang terbentuk pada hasil EEG di kanal TP9 dan TP10. Tidak terbentuknya gelombang pada kanal tersebut bisa dikarenakan belum adanya pengalaman ruang yang terbentuk pada setiap lokasi atau lokasi lain yang memiiki karakteristik yang sama atau memang belum mengetahui seiap lokasi tersebut khususnya Desa Rawabogo. Tidak munculnya gelombang atau memori yang dihasilkan menunjukkan belum dikenalnya Desa Rawabogo sebagai pilihan destinasi wisata. 


\section{Daftar Pustaka}

[1] F. Zakaria and D. Suprihardjo, "Konsep Pengembangan Kawasan Desa Wisata di Desa Bandungan Kecamatan Pakong Kabupaten Pamekasan," Tek. Pomits, vol. 3, no. 2, pp. C245-C249, 2014, doi: 2337-3520.

[2] A. Yuliana, I. Setyobudi, and S. Dwiatmini, "Fungsi Sosial dari Ritual Miasih Bumi Nagara Padang Bagi Masyarakat Kampung Tutugan Desa Rawabogo Kecamatan Ciwidey Provinsi Jawa Barat," J. Budaya Etn., vol. 3, no. 1, pp. 1-20, 2019.

[3] B. A. T. Sugiarto and Y. Siswantara, "Rumah Budaya Sebagai Ruang Publik untuk Mengembangkan Kegiatan Kepariwisataan di Desa Wisata Rawabogo," Lembaga

Penelitian dan Pengabdian kepada Masyarakat Universitas Katolik Parahyangan. 2012.

[4] G. Ngurah et al., "Factors That Influences Tourist's Satisfaction and Its Consequences," Eur. J. Bus. Manag. www.iiste.org ISSN, vol. 9, no. 8, pp. 39-50, 2017.

[5] J. Kandampully, "The impact of demand fluctuation on the quality of service: A tourism industry example," Manag. Serv. Qual. An Int. J., vol. 10, no. 1, pp. 1019, 2000, doi: 10.1108/09604520010307012.

[6] E. M. Armario, "Tourist Satisfaction: an Analysis of Its Antecedents," Hallowell Kozak Rimmingt. Pizam, pp. 367-382, 2008.

[7] S. Chatterjee and P. Mandal, "Traveler preferences from online reviews: Role of travel goals, class and culture," Tour. Manag., vol. 80, no. March, p. 104108, 2020, doi: 10.1016/j.tourman.2020.104108.

[8] M. H. Pestana, A. Parreira, and L. Moutinho, "Motivations, emotions and satisfaction: The keys to a tourism destination choice," J. Destin. Mark. Manag., no. December, pp. 1-9, 2019, doi: 10.1016/j.jdmm.2018.12.006.

[9] O. U. Qiong, "A Brief Introduction to Perception," Stud. Lit. Lang., vol. 15, no. 4, pp. 18-28, 2017, doi: 10.3968/10055.

[10] Q. Ma, L. Hu, G. Pei, P. Ren, and P. Ge, "Applying Neuroscience to Tourism Management : A Primary Exploration of Neurotourism,” vol. 671, pp. 1637-1640, 2014, doi: 10.4028/www.scientific.net/AMM.670-671.1637.

[11] I. G. A. N. Anglaya and I. W. Damayana, "Persepsi Warga Hindu Desa Adat Bualu Terhadap Pura Jagatnatha Puja Mandala Kuta Selatan, Badung, Bali," J. Psikol. Mandala, vol. 1, no. 2, pp. 29-36, 2019.

[12] E. Giudici, A. Dettori, and F. Caboni, "Neurotourism: Futuristic perspective or today's reality?," 20th Excell. Serv. Int. Conf., pp. 335-346, 2017.

[13] D. Wu and Y. Yu, "Electroencephalography (EEG) and Unconsciousness," Adv. Clin. Neurophysiol., no. October, pp. 30-54, 2012, doi: 10.5772/48346.

[14] S. Larry, D. Berg, F. Bloom, S. Du Lac, A. Ghosh, and N. Spitzer, Fundamental Neuroscience, 3rd Editio. Academic Press, 2008.

[15] Z. Myers, Wildness and Wellbeing: Nature, Neurosience and Urban Design. 2020.

[16] N. Oktar, "Theory of Neuroscience," J Neurol Sci Turk, vol. 23, no. 3, pp. 155158, 2006.

[17] A. Bastiyani and I. Safitri, "Arahan Pengembangan Pariwisata Di Kecamatan Dusun Selatan, Kabupaten Barito Selatan Propinsi Kalimantan Tengah," J. Perenc. Wil. dan Kota, vol. 13, no. 2, p. 125348, 2013, doi: 10.29313/jpwk.v13i2.1390.

[18] Nazir, Metode Penelitian. Jakarta: Ghalia Indonesia, 1998.

[19] Jasper, "How Perception Works," Brain Gymmer, 2020.

[20] M. A. Amarullah and I. Indratno, "Pengukuran Emosi Komunitas AKUR Cigugur 
terhadap Kegiatan Pembangunan dengan Aplikasi Neurosains Terapan," Pros. Perenc. Wil. dan Kota, vol. 7, no. 1, pp. 241-248, 2021, doi: http://dx.doi.org/10.29313/pwk.v7i1.26449.

[21] I. H. Agustina and H. Hindersah, "Explorations of social values in Magersari settlement in Indonesia," ISVS E-journal, vol. 6, no. 1, pp. 1-9, 2019.

[22] I. H. Agustina, "GIS approach to spatial analysis of heritage settlement: Case study of Magersari Kasepuhan palace, Indonesia,” J. Eng. Sci. Technol., vol. 16, no. 2, pp. 1614-1629, 2021.

[23] I. H. Agustina, A. M. Ekasari, I. Fardani, and H. Hindersah, "Local wisdom in the spatial system of the palace, Indonesia," IOP Conf. Ser. Mater. Sci. Eng., vol. 830, no. 2, 2020, doi: 10.1088/1757-899X/830/2/022077. 